\title{
BMJ Open COVID-19 confessions: a qualitative exploration of healthcare workers experiences of working with COVID-19
}

\author{
Paul Bennett (iD , ${ }^{1}$ S Noble, ${ }^{2}$ Stephen Johnston, ${ }^{1}$ David Jones, ${ }^{3}$ Rachael Hunter ${ }^{1}$
}

To cite: Bennett P, Noble S, Johnston S, et al. COVID-19 confessions: a qualitative exploration of healthcare workers experiences of working with COVID-19. BMJ Open 2020;10:e043949. doi:10.1136/ bmjopen-2020-043949

- Prepublication history for this paper is available online. To view these files, please visit the journal online (http://dx.doi. org/10.1136/bmjopen-2020043949).

Received 01 September 2020 Revised 24 November 2020 Accepted 30 November 2020

Check for updates

(C) Author(s) (or their employer(s)) 2020. Re-use permitted under CC BY-NC. No commercial re-use. See rights and permissions. Published by BMJ.

'Department of Psychology, Swansea University, Swansea, UK

${ }^{2}$ Division of Population Medicine, Marie Curie Research Centre, Cardiff University, Cardiff, UK ${ }^{3}$ Dept Anaesthetics and Critical Care, Prince Charles Hospital, Merthyr Tydfil, UK

Correspondence to Professor Paul Bennett; p.d.bennett@swansea.ac.uk

\section{ABSTRACT}

Objectives To gain insight into the experiences and concerns of front-line National Health Service (NHS) workers while caring for patients with COVID-19.

Design Qualitative analysis of data collected through an anonymous website (www.covidconfidential) provided a repository of uncensored COVID-19 experiences of frontline NHS workers, accessed via a link advertised on the Twitter feed of two high profile medical tweeters and their retweets.

Setting Community of NHS workers who accessed this social media.

Participants 54 healthcare workers, including doctors, nurses and physiotherapists, accessed the website and left a 'story'.

Results Stories ranged from 1 word to 10 min in length. Thematic analysis identified common themes, with a central aspect being the experience and psychological consequence of trauma. Specific themes were: (1) the shock of the virus, (2) staff sacrifice and dedication, (3) collateral damage ranging from personal health concerns to the long-term impact on, and care of, discharged patients and (4) a hierarchy of power and inequality within the healthcare system.

Conclusions COVID-19 confidential gave an outlet for unprompted and uncensored stories of healthcare workers in the context of COVID-19. In addition to personal experiences of trauma, there were perceptions that many operational difficulties stemmed from inequalities of power between management and front-line workers. Learning from these experiences will reduce staff distress and improve patient care in the face of further waves of the pandemic.

\section{INTRODUCTION}

There are limited qualitative data describing healthcare professionals' experiences during the COVID-19 pandemic. One small Chinese study by Liu et al reported core experiences to include duty of care, exhaustion due to heavy workloads and protective gear, fear of becoming infected and infecting others, feeling powerless to handle patients' conditions, and managing relationships. Social support was vital to managing their emotions. In a larger study of Flemish primary care doctors, Verhoeven et $a t^{2}$ found high levels of concern over becoming infected, the

\section{Strengths and limitations of this study}

The COVID-19 confidential website provided a safe context in which participants could offload stories of the care of COVID-19 patients with no fear of personal or professional consequences.

- The unprompted nature of the process ensured that the stories told were most important to participants.

- Recruitment via Twitter resulted in a biased sample, largely comprising medical personnel and twitter users.

emphasis on managing respiratory issues at the cost of non-COVID-19 problems, and the mental health consequences for vulnerable individuals. Sethi et al's study of 290 Pakistani health professionals found unprecedented workload and overstretched health facilities to be the dominant issues. ${ }^{3}$ While these studies will share commonalities, the experiences, perceptions and values of healthcare professionals may differ according to culture, healthcare system and governmental response to the pandemic. We, therefore, sought to gain insight into the experiences and concerns of front-line National Health Service (NHS) workers while caring for patients with COVID-19.

The study was undertaken through a simple online resource, advertised through Twitter, for front-line healthcare professionals to tell their COVID-19 story. The study was partly intended to provide a means of expressing and potentially moderating any distress participants may have experienced in the care of COVID-19 patients, but also actively encouraged the expression of more positive experiences. The emotional consequences of this process have been reported elsewhere. ${ }^{4}$ Here, we report the stories told by participants. 


\section{METHODS}

\section{Patient and public involvement}

The study did not involve patients. However, participant perspective was provided by coauthor, DJ, a consultant in intensive care medicine with a significant Twitter profile. His experiences of COVID-19 care and using social media to access healthcare professionals' views was invaluable in the design, conduct and reporting of this project.

\section{Data collection}

Data were collected between 14 March and 30 August 2020, during the first wave of COVID-19. Participants were recruited via Twitter, initially through the tweets of two doctors (intensive care and palliative care consultants) involved in the project who had a cumulative following of 38000 users. Targeted tweets regarding the project were also sent to medical Twitter 'influencers', with requests for retweeting and further dissemination. The tweets invited NHS colleagues to take part in a study in which they could record their experiences of care of patients with COVID-19 both as a potential means of dealing with stress and as a way of anonymously recording their experiences.

At the covid confidential webpage, participants were invited to 'securely and anonymously tell your COVID-19 story: your experiences, emotions, concerns, fears, as well as joyous or transforming experiences in the care of people with COVID-19' and informed that their 'stories' may be published in anonymous terms. They then completed a digital consent form and minimal demographic questionnaire (work role, gender and age), before recording their story verbally or in written form using the videoask.com website, which provided transcripts of verbal stories. There was a 5 min time limit

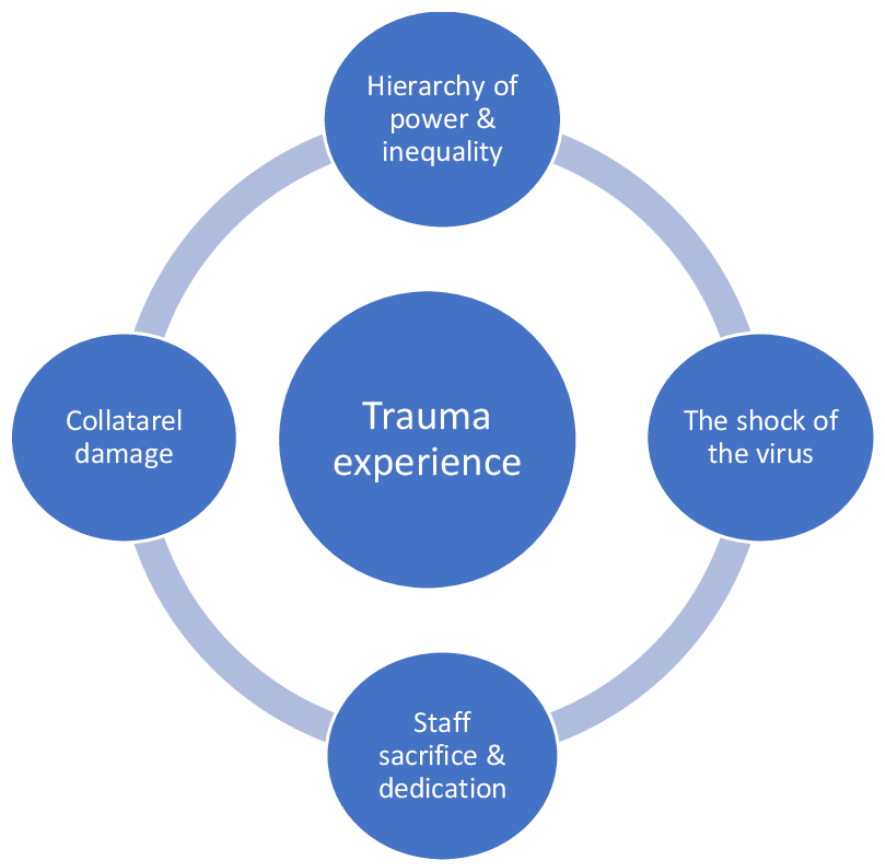

Figure 1 The five themes identified in the transcripts. for recording. One participant repeated this process to record $10 \mathrm{~min}$ of story. All audio recordings were deleted once transcribed.

In keeping with standard ethical practice, a participant information sheet was provided. It highlighted that due to the anonymous nature of the study, we could not identify any people experiencing distress as a consequence of participation or their experiences or refer them to support. In addition, participants were asked to complete a brief measure of immediate emotional change following this process, and these data were monitored at intervals through the study to safeguard against consistent negative effects of the storytelling. No adverse responses were recorded. On completion of recording their stories, participants were directed to a webpage which provided links to potential sources of support.

\section{Analysis}

Transcripts of all audio and written data were analysed using the inductive thematic analysis of Braun and Clarke. ${ }^{5}$ In this, transcripts were read repeatedly to ensure accuracy and enable the identification and generation of relevant initial codes and textual units for features and patterns in the data. Extracts and phrases were used to identify potential themes, with relevant data ('quotes') gathered within identified themes. Initial analysis was conducted by $\mathrm{RH}$ and the data were systematically reviewed by $\mathrm{PB}$ and others in the team to ensure that a name, definition and exhaustive set of data were identified to support each category. Regular reflective discussions were conducted ( $\mathrm{RH} / \mathrm{PB})$ throughout the study in keeping with best practice qualitative methodology. ${ }^{6}$

\section{RESULTS}

\section{Participants}

Fifty-four front-line healthcare workers in the NHS involved in the care of patients with COVID-19 told their story on the study website: covidconfidential.co.uk. Of these, 27 were doctors, 13 nurses, 2 physiotherapists, 1 radiographer, 1 healthcare assistant and 10 'other' including managers running services for COVID-19 patients. Their average age was 43.3 years (range 21-58 years). Sixteen were male, 34 female and 4 reported themselves as 'other' or non-binary. In addition, two doctors, one nurse and one medical student reported having minimal contact with COVID-19 patients. Their accounts are not reported here.

\section{Data availability}

Raw transcripts of the data analysed in the study are available from the lead author.

\section{Findings}

Thematic analysis was primarily conducted by $\mathrm{RH}$ and $\mathrm{PB}$, both of whom are now academic psychologists after having worked in the NHS as clinical psychologists earlier in their careers. This revealed five key themes 
(see figure 1). Themes are supported by verbatim quotes which also identify the role of the participant and the line/s at which the quote can be found in the raw data.

\section{The experience of trauma}

Participant accounts clearly identified a paradox for many working on the front line during COVID-19. Their work was both immensely rewarding and profoundly traumatic. However, the costs frequently outweighed the emotional benefits. Many talked about feeling 'broken' (Doctor, 197) by what was described as 'the horror that is COVID-19' (Nurse, 491). This language was used to depict how 'we ended up smashing ourselves and our trainees to pieces to get a vaguely safe rota' (Doctor, 322). The working environment felt brutal, and staff reported regularly feeling inadequate and overwhelmed:

I felt so inadequate and tried my very best to make sure these poor patients had anticipatory medication. Staff were in tears and I watched a group of cardiology nurses cry as they tried to cope with patients with severe covid. (Nurse, 737-737).

The impact of working on the front line in this pandemic was described as 'affecting staff mentally, emotionally, psychologically and physically' (Nurse, 303-304). Trauma-related symptoms were common, with descriptions of intrusive, vivid and traumatic thoughts or memories, as well as emotional numbing:

I think what I really feel is quite numb (Nurse, 802)

I think about it all the time. I think about all those people that died in the beginning alone. And I also really think about the patients that we discharged who are with us for 50 odd days who will never ever get back to what they were like before. (Physiotherapist, 38-40)

Nothing will ever prepare a person for having to tell a family their loved ones have died over the phone or standing there holding an ipad as they watch their dad pass away via a video link. (Nurse 492-493)

Participants also reported a wider impact on their life and relationships whether in the short-term 'I'm actually hiding from my family a little bit.' (Nurse, 803); 'My partner is now, uh, moved out. So, uh, it's had a huge impact on my life.' (Doctor, 615-616)) or the future: 'I think I will be revaluating my career path after this.' (Nurse, 223).

Patient trauma was also highlighted, with devastating descriptions of psychological trauma among surviving intensive therapy unit patients:

They don't sleep. They have nightmares. They think that you know, one man doesn't sleep because he's worried that if he goes to sleep, he'll never wake up again. Another man still thinks sometimes that his family are dead or that he, you know, his family sold him to some sort of slave trader, you know, those delirium kind of nightmares just haven't gone away. (Physiotherapist, 57-61)

\section{The 'shock' of the virus}

Workers described how they had 'never seen so many... so many people who were so sick.' (Physiotherapist, 4-5); 'some of the sickest I've ever seen.' (Nurse, 467-468). They were shocked by the physical and psychological brutality of the virus; separating families in their most desperate hour:

They were the most sick people I've ever seen and there are so many people dying and we weren't allowing any visitors. The thought of people saying, 'bye to relatives via Skype just absolutely broke me every single day, and I cried and cried and cried about it when I got home. (Physio, 8-11).

Staff were often shocked by who was vulnerable to the virus. One participant described how "we are getting our eyes opened because this disease does not discriminate.' (Other, 777). Indeed, some were shocked just how many young or middle-aged people were affected: 'And young people! Not as the media would portray these elderly vulnerable with underlying medical conditions.' (Doctor, 171-172). COVID-19 does, however, disproportionately affect older people and this rendered many senior clinicians as highly vulnerable and consequently impacted on workforce availability:

We were told of course that it should be the most senior person intubating, but also that they were the people probably at highest risk! And so I can see the look almost a fear in the eyes of some of my consulting colleagues. (Doctor, 182-184)

There was broad agreement that services were "unprepared' for COVID-19, personally and organisationally:

I certainly wasn't prepared for the horror that is covid-19, anyone that says they were is a liar. (Nurse, 490-491)

Before the government announced anything, we pulled together a team as we realised we could quickly be getting cases but were not prepared for it. (Nurse, 904-907)

Living and working through this pandemic was described as 'a world disaster. Hopefully once in a lifetime experience.' (Doctor, 429), but also a shared experience that patients and front-line staff had faced together:

I found myself on a night shift on ITU (intensive therapy unit) with a gentleman on everything. 'Kid, you shouldn't be here, and I shouldn't be here'. And how weird and strange it was that we were both here! (Nurse, 807-809) 


\section{Staff sacrifice and dedication}

The dedication of staff and their commitment to fulfil their duty of care was described as 'Herculean...the extra work and hours that have been put in to support the NHS.' (Nurse, 930-931). This is in spite of the practical and emotional challenges faced:

My clinical colleagues have been unbelievable. Adaptable, honest, efficient, true to patient need. Facing fear head on. Maintaining polite lines of conversation despite internally screaming at management types that it's too little, too late. (Doctor, 449-451)

We have bent over backwards to flex towards patient need. At less than $6 \mathrm{hr}$ notice not infrequently. Many of us now have covid but there hasn't been a shift unfilled. We want to step up to demand, for our patients and organisation. Yet... HR are demoralising us. (Doctor, 193-196)

Fears of infection were influenced by experiences of caring for the most unwell patients. People described the risk of infection as 'as something that was inevitable.' (Doctor, 886) but many were terrified and traumatised:

If I'm not crying because I'm scared of getting ill or infecting my loved ones, then I'm awake at $3 \mathrm{am}$ after hearing families sob their hearts out because they cannot hold their loved ones in their last moments. (Nurse, 493-496).

Importantly, the unprecedented and unique challenges of COVID-19 meant that new ways of working had to be adopted and standards may be compromised:

You have to change the way they are nursed, they don't respond to things in the usual way or within usual time limits. This is hard when you've spent years learning now best to do something, it's like you're new to ITU again. (Nurse, 467-470)

They can't work within their values. They can't do the care they want to provide. And I've been talking to them [staff] a lot about seeing that feeling as 'moral injury' because that's what they're experiencing. (Doctor, 895-897)

At the heart of testimonies, however, were descriptions of patient focussed care with many describing being 'proud of myself' (Nurse, 594) and how 'my patients are hugely important to me, at these times more than ever. I have a personal responsibility to them' (Doctor, 427-428). This dedication was also seen in the descriptions of 'a kind of survivor guilt' (Doctor, 645) when forced into redeployment due to health risks. Herein staff were left feeling 'worthless and guilty about not doing my bit for the NHS.' (Doctor, 708).

\section{Collateral damage}

Participant accounts were punctuated by regular descriptions of the repercussions, or 'collateral damage' of
COVID-19. This ranged from the 'inevitable' (Doctor, 886) nature of contracting the virus, to inappropriate levels of risk forced on staff:

We wanted to make changes but were not heard. We've had staff die on our wards. I was reprimanded for wearing gloves and a pathetic "pinnie [apron] on the ward before one member of staff member died, because it wasn't approved policy yet and we would worry patients. (Doctor, 451-454)

There were frequent concerns relating to marginalised and vulnerable groups, with reports of inadequate risk assessments as well as a description of inappropriate 'do not resuscitate' instruction both highlighted:

The response of my organisation to the employees of BAME (black, Asian, and minority ethnic) origin has left me feeling bitter. In fact; appalled. My colleagues deserve so much more than a prefilled risk assessment, sent awaiting a signature. Surely inviting a person to discuss is the first point of any risk conversation. WHY WOULD THIS EVER BE OVERLOOKED?! We have lost three staff... How many more! (Doctor, 208-212)

My work is with people with learning disabilities and I have seen how they have been marginalised even more than they have been prior to the advent of the pandemic. I have been asked on more than one occasion to clarify DNAR status when I believe that this is inappropriate. (other, 580-583)

Significantly the health repercussions of continued lockdown, as cases of COVID-19 declined, were indicated as being serious and far reaching for people with mental health issues:

Only two patients on ITU have Covid. The rest are people at deaths door from suicide attempts. All have a history of mental illness, all known to mental health services. All having had a sequential deterioration over the lockdown period with reduction in mental health support services, community projects, peer support, drop ins etc. What I am seeing is the tip of the iceberg: those whose suicide attempts are not successful but bad enough to need ITU. What of all the others who are managed on non-critical care beds? What of those who are turned around quickly in A and $\mathrm{E}$ in order to minimise admissions. We are beginning to get a picture of the knock-on effects of this pandemic. (Doctor, 134-141)

Some participants felt that responses to COVID-19 and the subsequent reorganisation of services had led to some poor decision making which was affecting patient care broadly, with 'people coming in with very serious problems which were being missed' (Doctor, 500-503). Relatedly, inadequate assessment of risk for patients and their places of discharge was also described, highlighting the context of services already struggling to cope before the pandemic: 
Something that usually takes years in the NHS happened over night with not enough realisation at the top of organisations quite what was happening. The government encouraged discharges to care homes with no testing system in place, saying it was low risk (Nurse, 913-918)

Where's the support going to come from for these people? There are no Community Services! You know, we're discharging people to their homes and there's no physio. There's no OT. There's no carers. There's no psychological support. [...]. You know that there was never any of their stuff for people that have had lengthy ITU days before; this is not a new thing but there's just so many of them now (Physiotherapist, $68-73)$

It seemed impossible for these concerns to be raised without it being regarded as critical and unhelpful for morale:

I also think is a problem that people are able to accept that we are providing substandard care to everyone other than those with covid. It, um I don't know what the solution is. It's very hard knowing how to raise this. Not so much a whistleblowing as it was, just a public safety issue. But people are working hard. People are getting tired now and the last thing they need is for people to turn around and say, 'Oh, by the way, you're all crap'. (Doctor, 513-517).

\section{Hierarchy of power and inequality}

There was a widely reported disconnect between senior management and front-line staff, with clinicians' views and requests frequently reported as being disregarded:

We weren't prepared. We were not ready. Immediately before the first wave hit our Hospital, we'd been begging Hospital management staff to cancel elective surgery because we started to see cases and we knew what was coming. They ignored our requests. (Doctor, 158-160)

I'd like to be able to say, 'in hindsight, we would have done differently'. The fact is, us clinicians knew all along at the time. And our voices were quashed in a sea of management meetings, who frankly were rearranging deckchairs rather than encouraging us to make the changes we needed to make. Exec. teams must be led by clinicians and supported by managers. Not vice versa. I'm angry because I believe we were not heard. (Doctor, 455-460)

Participants felt that risk was disproportionately assigned to the front line and that those who were most vulnerable were not adequately protected:

I work with others that have a lot to lose. Either from ethnicity, age, comorbidity. And yet they show up day after day. Certain senior colleagues have vanished under one guise or another. What gets my goat is their instructions, advice and criticisms from afar. They are largely white. Sadly, more men than women too. (Doctor, 412-415)

Covid-19 has exposed innumerable inequalities. I thought I was aware. I am not. I'm learning that organisations are powerful. How do the BAME frontline workers get heard?! (Doctor, 212-213)

If anything, please can we take from this, that a white middle class manager, working from HOME has absolutely NO PLACE in assigning risk to any front-line staff seeing febrile and sick unscreened patients daily. That has happened to BAME employees in my organisation. (Doctor, 417-420)

Many participants felt abandoned by their organisation and "poorly supported trainees felt like being left as sacrificial fodder' (Doctor, 722-724). Frequently frustrations and conflict emerged between staff groups, notably where GPs 'won't see anyone but us nurse practitioners are expected to' (Nurse, 126-127).

While some participants did report cohesive and supportive team working and management, the majority described a sense of abandonment by management and described anger that 'the government failed us all' (Nurse, 929). This lack of support, combined with high levels of trauma created a sense of feeling hopeless and left many staff feeling disillusioned about their career and organisation:

I've never felt more detached from senior management. After this is over, I'm going to seriously reflect on whether I feel this is an organisation I want to work for and with. I'm seeing it in a different light. I no longer think this is for me. (Doctor, 291-294).

The 'talk' of management has been great, especially as staff died. Their actions however have been pitiful. In fact, insulting to those that have died as both patients and staff. Yet I have very limited faith anyone will personally realise, what they could have done which would have helped (Doctor, 421-424)

There was a sense of staff waiting for government guidance which was 'non-existent but then came thick and fast-as soon as you implemented something everything changed again' (Nurse, 913-914) and this fuelled anxieties about best practice. More broadly, staff felt a personal mistrust of government. One particular 'flash-point' for these views emerged around publicity regarding a senior government advisor, Dominic Cummings, who apparently broke lockdown rules:

We want proper credible leadership which listens to experts, values its staff and its population. I don't think I have ever been so angry with a government as this one over their behaviour over covid-19 and Cummings in particular (Doctor, 144-146) 
Families were giving up so much! And in fact, this one [paediatric oncology patient] may have limited time left .... Was giving up so much! And this man [Dominic Cummings] is allowed to break rules with impunity and treat the public with such disregard and such contempt that they feel like they can get away with it. Really?! ...um I think the experiences I've had the last few weeks have been very, very different to any I've had before. And it feels quite personal when Dominic Cummings is being defended on TV by the Prime Minister. (Doctor, 382-387)

\section{CONCLUSION}

This study aimed to gain better understanding of the experiences and concerns of front-line NHS workers while caring for patients with COVID-19. Previous qualitative data from China, Belgium and Pakistan highlighted concerns regarding intensity of workloads, concerns regarding infection and overstretched facilities. ${ }^{1-3}$ By using an anonymised online platform, we were able to gain uncensored access to their stories, which may account for the additional themes emerging from our data corpus. Key findings highlighted that while healthcare workers shared intensely positive experiences, caring for COVID-19 patients brought a significant emotional toll, and strained relationships between immediate frontline staff, their families, management and even government. There was a sense that in the beginning of the pandemic, staff were driven by adrenalin and optimism; but over time this dissipated to be replaced by exhaustion, numbness and dread expectation of a 'second wave'. Healthcare workers could reasonably be considered as 'second victims' of COVID-19. The stories reflected not only the personal horror of caring for profoundly ill patients who were not responding to treatment, but also wider societal concerns including the failure to test older people being discharged to care homes, and the emerging evidence of 'long COVID-19': a key future challenge for the NHS. Finally, anger over the chief advisor to the UK Prime Minister's apparent breaking of lockdown perhaps encapsulated wider fears and anger towards those not adhering to recommended behavioural guidelines. Other issues were raised by respondents, although not in sufficient numbers to consistently include as a 'theme'. On participant, for example, considered the weekly 'Clap for the NHS' to be showing solidarity with, and care for, NHS workers, while another considered it 'virtue signalling' and patronising. There were no consistent positive themes.

Loyalties and fears of legal/organisational repercussions may result in understandable silences among many NHS workers. This suppression denies access to honest descriptions from staff from which many important lessons can be learnt. This confidential and anonymous method of data collection enabled us to bypass that censorship and as such, the data collected here provides valuable insight into the experiences of healthcare workers at a time of extreme crisis.
It is important to acknowledge the limitations of this study. The study sample was small, particularly when considering the NHS employs over 400000 doctors and nurses and while the recruiting tweets were disseminated widely, there is likely to be sample bias since not all healthcare workers engage with social media. The recipients are likely to have been restricted to a particular vocal and engaged subgroup of healthcare practitioners and those who were motivated to engage with the study may have had a particular story they wanted to tell. Finally, while every effort was made to simplify the covid confidential website, engagement still required a degree of effort and it is possible that the views expressed represented the more extreme experiences leading to the most motivated participation. From a methodological perspective, without the use of prompts to explore other potential viewpoints, we cannot ensure data saturation and exploration of these or future data according to profession, gender and age may further unravel key issues.

Any strategic response to these stories would need be complex and multifactorial, and are not always easy to implement in a rapidly changing context at a local level. But some can be addressed. At a systemic level, the voices of workers at the front-line need to be heard and the effects of stress mitigated. There were clear rifts between 'workers' and 'management', senior and junior colleagues, and those with more or less power within the system. While these may not be novel findings in the NHS, they are amplified at a time of crisis, and cannot be ignored. Pathways of communication between each group, and subgroups within them (such as people from black, Asian and minority ethnic backgrounds or those with legitimate personal health concerns) need to be established or re-established and respected within units of healthcare provision. A number of authors have detailed potential responses to mitigate the impact of COVID-19 care on health professionals ${ }^{78}$ and these will not be further rehearsed here. However, as one example of the wider context of these issues, the NHS employers website (https://www.nhsemployers.org/) notes that 30\% of staff do not feel able to talk openly to their line manager about stress, while $56 \%$ of employers said they would like to improve staff well-being but did not know how to. The website provides access to the NHS Health and Wellbeing Framework which offers both organisational and individual strategies for change. Wider implementation of these existing strategies may be of significant benefit. We already have the tools to resolve many of these problems; they simply need to be implemented.

\section{Twitter S Noble @simonnoble}

Contributors PB: lead author of submitted paper, study design and analysis. RH: led analysis, contributed to study design and final submission. SJ: website design, setup and contributed to final submission. SN: contributed to study design, analysis and final submission. DJ: contributed to study design and final submission.

Funding The authors have not declared a specific grant for this research from any funding agency in the public, commercial or not-for-profit sectors.

Competing interests None declared. 
Patient and public involvement Patients and/or the public were not involved in the design, or conduct, or reporting, or dissemination plans of this research.

Patient consent for publication Not required.

Ethics approval Ethical consent for the study was granted by the ethics committee of the Department of Psychology, Swansea University: approval number 4484.

Provenance and peer review Not commissioned; externally peer reviewed.

Data availability statement Data are available on reasonable request. Raw transcripts of the data analysed in the study are available from the lead author.

Open access This is an open access article distributed in accordance with the Creative Commons Attribution Non Commercial (CC BY-NC 4.0) license, which permits others to distribute, remix, adapt, build upon this work noncommercially, and license their derivative works on different terms, provided the original work is properly cited, appropriate credit is given, any changes made indicated, and the use is non-commercial. See: http://creativecommons.org/ licenses/by-nc/4.0/.

\section{ORCID iD}

Paul Bennett http://orcid.org/0000-0003-2252-6065

\section{REFERENCES}

1 Liu Q, Luo D, Haase JE, et al. The experiences of health-care providers during the COVID-19 crisis in China: a qualitative study. Lancet Glob Health 2020;8:e790-8.

2 Verhoeven V, Tsakitzidis G, Philips H, et al. Impact of the COVID-19 pandemic on the core functions of primary care: will the cure be worse than the disease? A qualitative interview study in Flemish GPs. BMJ Open 2020;10:e039674.

3 Sethi BA, Sethi A, Ali S, et al. Impact of coronavirus disease (COVID-19) pandemic on health professionals. Pak J Med Sci 2020;36 (COVID19-S4:S6-11.

4 Bennett P, Hunter R, Johnston S, et al. Covid-19: recording their stories provides emotional benefit to healthcare workers. BMJ 2020;369:m2536.

5 Braun V, Clarke V. Using thematic analysis in psychology. Qual Res Psychol 2006;3:77-101.

6 Ortlipp M. Keeping and using reflective journals in the qualitative research process. Qual Rep 2008;13:695-705.

7 Zaka A, Shamloo SE, Fiorente P, et al. COVID-19 pandemic as a watershed moment: a call for systematic psychological health care for frontline medical staff. J Health Psychol 2020;25:883-7.

8 Tracy DK, Tarn M, Eldridge R, et al. What should be done to support the mental health of healthcare staff treating COVID-19 patients? Br J Psychiatry 2020;217:537-9 